\title{
Impacts of Ethanol on Planted Acreage in Market Equilibrium
}

\author{
Hongli Feng and Bruce A. Babcock
}

Working Paper 08-WP 472

June 2008

\author{
Center for Agricultural and Rural Development \\ lowa State University \\ Ames, lowa 50011-1070 \\ www.card.iastate.edu
}

Hongli Feng is an associate scientist in the Center for Agricultural and Rural Development (CARD) and an adjunct assistant professor in the Department of Economics; and Bruce Babcock is director of CARD and professor in the Department of Economics; both at lowa State University.

The authors acknowledge support from the Great Lakes Bioenergy Research Center (GLBRC), Grant No. DE-FC02-07ER64494.

This paper is available online on the CARD Web site: www.card.iastate.edu. Permission is granted to excerpt or quote this information with appropriate attribution to the authors.

Questions or comments about the contents of this paper should be directed to Hongli Feng, 578 Heady Hall, lowa State University, Ames, lowa 50011-1070; Ph: (515) 294-6307; Fax: (515) 294-6336; E-mail: hfeng@iastate.edu. 


\begin{abstract}
Land use impacts of biofuel expansion have attracted a tremendous amount of attention because of the implications for the climate, the environment, and the food supply. To examine these impacts, we set up an economic framework that links input use and land allocation decisions with ethanol and agricultural commodity markets. Crops can be substitutes or complements in supply depending on the relative magnitude of three effects of crop prices: total cropland effect, land share effect, and input use effect. We show that with unregulated free markets, total cropland area increases with corn prices whether crops are substitutes or complements in supply. Similarly, higher corn yields from exogenous technical changes lead to cropland expansion. The impacts of yield increases for other crops are ambiguous. With a quantity mandate for ethanol, higher mandates mean larger cropland area if corn and other crops are substitutes in demand. For a given mandate, yield improvement causes total cropland to expand if crop demand is elastic enough, or to contract under a very general condition if crop demand is sufficiently inelastic.
\end{abstract}

Keywords: biofuels, complements in supply, ethanol, (in)direct land use changes, substitutes in supply, yield increases. 


\section{Impacts of Ethanol on Planted Acreage in Market Equilibrium}

\section{Introduction}

The urgency of assessing the impacts of biofuels on land use is underscored by two recent events. First, the Energy Independence and Security Act of 2007 (EISA) directs the government to support the development of analytical tools for assessing greenhouse gas emissions of biofuels, including "emissions related to direct and indirect land use changes." Second, recent research, notably two articles published in Science, has shown that instead of mitigating climate change, the use of biofuels may actually increase greenhouse gas emissions when land use impacts are taken into account (Searchinger et al. and Fargione et al.). To what extent biofuels can reduce greenhouse gas emissions is vital to the future of the sector because EISA requires that carbon reduction thresholds be met before biofuels can be counted as contributing toward mandates. Besides this federal government requirement, California and many other states have established low carbon standards for transportation fuels. The appropriate assessment of land use changes, which are often associated with large changes in carbon emissions, will be essential to the assessment of the greenhouse impacts of biofuels.

Despite the importance of the issue, it is not clear just how land use changes should be assessed. There is even skepticism about whether land use changes can be rigorously modeled. Land use changes as a result of biofuel production are often divided into direct and indirect land use changes. Different definitions have been given to these seemingly straightforward concepts (e.g., Wang and Haq, and O'Hare). In general, it appears that direct land use changes refer to changes directly associated with the production of feedstock for biofuels. Any other land-related changes are considered indirect land use changes. According to Dale, while direct land use change is a legitimate subject, the "indirect land use change caused by biofuel production is tenuous, uncertain and highly speculative." 
To date, most studies that examine the land use impacts of biofuels do not consider market reactions in response to biofuels production (e.g., Feng et al., Righelato and Spracklen, and Fargione et al.). Feng et al. pointed out that carbon emissions on land before and during land conversion can be larger than the emissions avoided by biofuels. Similarly, Righelato and Spracklen, and Fargione et al. compared the carbon impacts of using land for biofuels versus using the same land directly as a carbon sink through trees, grasses, and/or soil. Both studies found that the latter outweighed the former in its impact. How biofuels production changes crop prices, how price changes induce the clearing of forests or other land, and how corn and other crops compete for cropland were not examined in these studies.

There are only a handful of studies thus far that take into account crop markets in estimating land use impacts of biofuels. In Searchinger et al., crop supply and demand were studied in the context of international commodity markets. They estimated new demand for cropland and then assigned it to different regions based on historical conversion patterns that might not be plausible in the context of biofuel expansion. Keeney and Hertel performed a comprehensive general equilibrium analysis on the land use impacts of biofuels. Real-world market forces were well represented by their simulation framework. However, it is often challenging for non-expert readers to see interactions among essential drivers because they are contained in the "black box" of the simulation models. Further, as acknowledged by Birur et al. in a related analysis, the usefulness of these models is limited by the availability and quality of data, and this can also be a source of criticism of analyses based on such models. Given the skepticism surrounding land use modeling, simple and transparent analyses can facilitate an understanding of fundamental issues.

In this paper, we develop a simple but rigorous analytical framework that embodies major essential economic forces affecting land use decisions: the allocation of land between crops, input use, crop markets and prices, land markets, and yield improvement. Our analysis is closely related to the large literature on land allocation and input use decisions that has no direct 
connection to biofuels (e.g., Arnade and Kelch, Orazem and Miranowski, Chavas and Holt). In most of these papers, the acreage allocation decisions are considered for a given fixed total cropland area. In our paper, we link the acreage allocation decisions with responses in total cropland area. We show how changes in crop supply are determined by adjustments in input use, land share, and total cropland area.

Through the integrated framework of ethanol and land use decisions, we study the drivers behind land use changes in different policy contexts: (i) a laissez-faire environment without government intervention; (ii) government subsidies for ethanol production; and (iii) government mandates on ethanol quantity, which can act as either minimums or maximums that constrain the ethanol industry. Yields can have major impacts on land use changes. Higher yields have been touted as a key solution to the competition between food, fuel, and wilderness (Farrell, Monsanto, and Zulauf). However, if higher yields mean more profitable farming, yield increases could induce cropland expansion. Within our analytical framework, we are able to make some general predictions with regard to the land use impacts of higher biofuel prices or government incentive programs. The role of higher yields is shown to be different under different policy scenarios.

We begin our analysis by laying out the components of the modeling framework. We then analyze the responses of endogenous variables to price changes. Finally, we use these responses to examine acreage adjustments at market equilibrium under different scenarios.

\section{Modeling framework}

\subsection{Land use and commodity supply}

The supply of agricultural commodities depends on the allocation of land between crops, land quality, input use, and total cropland area. To reflect land heterogeneity, each parcel of land is associated with a land quality index, $\theta$, indicating yield potential. The index is normalized to between zero and one, i.e., $\theta \in[0,1]$. Higher $\theta$ means lower quality: the best land has $\theta=0$ while the worst land has $\theta=1$. Total land that could be planted to crops is normalized to one. 
The probability distribution function of land is denoted as $u(\theta)$. Then, the amount of land with $\theta \leq \hat{\theta}$ is $\int_{0}^{\hat{\theta}} u(\theta) d \theta$

We use $i$ as a crop index, with $i=c$ for corn and $i=o$ for other crop representing all other crops. The yield of crop $i, y_{i}$, is determined by input use (e.g., fertilizers and chemicals) and cropland allocation for any given $\theta$. Let $z_{i}$ be the input use on crop $i$ and $\alpha_{i}$ be the share of cropland devoted to crop $i$. Then we can denote $y_{i}$ as a function of $z_{i}$ and $\alpha_{i}$, i.e., $y_{i}\left(z_{i}(\theta), \alpha_{i}(\theta) ; \theta\right)$, which is assumed to be continuous and twice differentiable in the arguments. ${ }^{1}$ Both $\alpha_{i}$ and $z_{i}$ are written as a function of $\theta$ because they may vary with land quality. We assume that $y_{i}(\cdot)$ is concave and increasing in $z_{i}$, i.e., $y_{i}^{z_{i}}>0$ and $y_{i}^{z_{i} z_{i}}<0 .{ }^{2}$ Better quality land has a higher yield, that is, $y_{i}^{\theta}<0$. We also allow for the possibility that the yield of a crop may drop as a greater share of cropland is devoted to that crop. For example, in Iowa, corn is generally grown in rotation with soybeans. As a greater share of land is devoted to corn, it is likely that more corn will be planted after corn. The yield drag of continuous corn production is well documented (Hennessy). Thus, we assume $y_{i}^{\alpha_{i}} \leq 0$. Note that we do not model rotation explicitly, even though $y_{i}^{\alpha_{i}} \leq 0$ is used to capture some rotational effects.

The output of crop $i$ on land of quality $\theta$ is equal to yield multiplied by the area devoted to the crop. Let output and input prices be $p_{i}$ and $w$, respectively. Then we can write the net return from farming land of quality $\theta$ as ${ }^{3}$

$$
\pi(z, \alpha ; \theta)=\sum_{i=c, o}\left[p_{i} y_{i}\left(z_{i}(\theta), \alpha_{i}(\theta) ; \theta\right)-w z_{i}(\theta)\right] \alpha_{i}(\theta) u(\theta)
$$

\footnotetext{
${ }^{1}$ To economize notation, note that we use $y_{i}$ to indicate both the yield function and the value of the yield function.

${ }^{2}$ Superscripts indicate derivatives, e.g., $y_{i}^{z_{i}} \equiv \frac{\partial y_{i}\left(z_{i}(\theta), \alpha_{i}(\theta) ; \theta\right)}{\partial z_{i}}$ and $y_{i}^{z_{i} z_{i}} \equiv \frac{\partial^{2} y_{i}\left(z_{i}(\theta), \alpha(\theta) ; \theta\right)}{\partial z_{i}^{2}}$.

${ }^{3}$ Here, as in rest of the paper, bold letters represent vectors, i.e., $z \equiv\left(z_{c}, z_{o}\right)$ and $\alpha \equiv\left(\alpha_{c}, \alpha_{o}\right)$.
} 
For any given $\theta$, net return is maximized through decisions on two variables: land allocation between crops and input use for each crop. That is, the following optimization problem is solved given input and output prices:

$$
\max _{z, \alpha} \pi(z, \alpha ; \theta) \quad \text { such that } \sum_{i=c, o} \alpha_{i}(\theta)=1, \text { and } z_{i}(\theta) \geq 0 .
$$

Assuming interior solutions, we can write the first-order conditions of (2) as

$$
\begin{gathered}
{\left[p_{c} y_{c}^{*}+p_{c} y_{c}^{\alpha_{c}^{*}} \alpha_{c}^{*}-w z_{c}^{*}\right]-\left[p_{o} y_{o}^{*}+p_{o} y_{o}^{\alpha_{o}^{*}} \alpha_{o}^{*}-w z_{o}^{*}\right]=0 \text { and }} \\
p_{i} y_{i}^{z_{i}^{*}}-w=0,
\end{gathered}
$$

where "*” indicates optimal solutions. We assume that the second-order conditions are satisfied. The optimal land share and input use are functions of both commodity prices and land quality, and so the full notation for them is $\alpha_{i}^{*}(\boldsymbol{p} ; \theta)$, and $z_{i}^{*}(\boldsymbol{p} ; \theta)$, respectively. Equation (3) requires that the marginal net return from a change in land share is equalized between corn and other crop. Equation (4) means that the marginal revenue from an increase in input use equals the marginal cost for each crop.

The optimized net return is higher for better land because better land has a higher yield for any given land allocation and input use. Mathematically, this means

$$
\pi(z, \alpha ; \theta)>\pi\left(z, \alpha ; \theta^{\prime}\right) \quad \text { for any } \theta<\theta^{\prime} \text {. }
$$

In the long run, additional land will be brought into agricultural production as long as net return from farming is positive. ${ }^{4}$ Denote the quality range of land in production as $\left[0, \theta^{*}\right]$, implying that total cropland area is $\int_{0}^{\theta^{*}} u(\theta) d \theta$. Given (5), this means that in equilibrium, we have

$$
\pi\left(z^{*}\left(\boldsymbol{p} ; \theta^{*}\right), \alpha^{*}\left(\boldsymbol{p} ; \theta^{*}\right) ; \theta^{*}\right)=0 .
$$

Thus, $\theta^{*}$ is a function of $\boldsymbol{p}$; i.e., in equilibrium the quality of the marginal land depends on crop prices. The decisions on land share and input use and the optimal total cropland area will

\footnotetext{
${ }^{4}$ The assumption that marginal cropland has zero net returns will be true if marginal land is not used before conversion. Assuming a positive constant net return to marginal land will not change our results.
} 
determine the supply of crops. Summing over land of different quality, the total supply of crop $i$ is

$$
Q_{i}^{S}(\boldsymbol{p})=\int_{0}^{\theta^{*}(\boldsymbol{p})} y_{i}\left(z_{i}^{*}(\boldsymbol{p} ; \theta), \alpha_{i}^{*}(\boldsymbol{p} ; \theta) ; \theta\right) \alpha_{i}^{*}(\boldsymbol{p} ; \theta) u(\theta) d \theta
$$

\subsection{Ethanol market}

Progress in technology determines the rate of conversion from corn into ethanol. We use $v_{c, e}$ to denote the amount of ethanol that can be derived from one unit of corn. The current conversion rate is about 2.8 gallons per bushel of corn. Technology also determines the amount of energy needed to produce ethanol from corn. Let $v_{c, f}$ be the amount of energy needed to refine one unit of corn. For simplicity, we assume that ethanol is the only output and energy is the only input at ethanol plants, even though there are other outputs (e.g., distillers grains) and other inputs (e.g., enzymes and labor). Considering these factors will not change our main results but will make exposition more complicated.

Let $p_{e}$ and $p_{f}$ be the price of ethanol and its input, respectively. Ethanol producers choose the quantity of ethanol to maximize profit for given technology and prices, i.e.,

$$
\begin{aligned}
\max _{Q_{c}} \pi_{e} & \equiv p_{e} Q_{e}-p_{c} Q_{c}-p_{f} Q_{f} \\
& =p_{e} v_{c, e} Q_{c}-p_{c} Q_{c}-p_{f} v_{c, f} Q_{c}
\end{aligned}
$$

where $\pi_{e}$ is the profit from ethanol production; $Q_{i}$ is the quantity of commodity $i$ for $i$ representing ethanol, corn, and energy. We assume for most of our analysis that the ethanol price is exogenously given, i.e., not affected by the amount of ethanol produced. This will be a reasonable assumption as long as ethanol's share among transportation fuels is very small and so its price is essentially determined by gasoline prices. Currently, ethanol accounts for less than $5 \%$ of gasoline consumption (on an energy equivalent basis) in the United States and so demand is quite elastic. Results developed under this assumption will also hold for some range of demand 
elasticity that is less than perfectly elastic. When ethanol production substantially increases, it is necessary to consider that the ethanol price is endogenously determined in conjunction with the markets for transportation fuels.

The long-run equilibrium condition for ethanol production is

$$
\frac{\partial \pi_{e}}{\partial Q_{c}}=p_{e} v_{c, e}-p_{c}-p_{f} v_{c, f} \leq 0, \quad \frac{\partial \pi_{e}}{\partial Q_{c}} Q_{c}^{e D}=0, \quad Q_{c}^{e D} \geq 0 .
$$

where $Q_{c}^{e D}$ is the equilibrium demand for corn in ethanol production. The above condition requires that the marginal profit from ethanol equals zero if ethanol is produced at all. We can express the demand for corn from ethanol plants as follows:

$$
\begin{aligned}
& \text { if } p_{c}=p_{e} v_{c, e}-p_{f} v_{c, f} \text {, then } Q_{c}^{e D}\left(p_{c}\right)=a n y ; \\
& \text { if } p_{c}>p_{e} v_{c, e}-p_{f} v_{c, f}, \text { then } Q_{c}^{e D}\left(p_{c}\right)=0 .
\end{aligned}
$$

Thus, the demand for corn from ethanol production is perfectly elastic for given ethanol and corn prices that satisfy the equality condition in (10). This equality condition indicates that in the long-run equilibrium, the corn price is given for a given ethanol price: $p_{c}$ is equal to the value of ethanol from one bushel of corn, subtracting any cost incurred in the conversion process.

\subsection{Commodity markets}

Besides ethanol, corn is also used for other purposes, primarily as a food source through livestock production. Denote corn demand for these non-ethanol uses as $Q_{c}^{f D}(\boldsymbol{p})$, which is a function of the prices of corn and other crop to account for substitutability between the crops. Total demand for corn is the sum of demand from animal production and demand from ethanol plants. The left panel of Figure 1 presents an illustration of the corn market. The kink on the demand curve occurs at the breakeven corn price $p_{c}$ in ethanol production, which is also the equilibrium price. At this price, corn used for animal and ethanol production is $Q^{1}$ and $\left(Q^{2}-Q^{1}\right)$, respectively. The right panel illustrates the impacts of a higher corn price, $p_{c}^{\text {new }}$, 
resulting from, say, higher oil price. The horizontal part of the total demand curve shifts up. In the new equilibrium, food consumption of corn decreases by $\left(Q^{1}-Q^{1, n e w}\right)$ and corn production increases by $\left(Q^{2, \text { new }}-Q^{2}\right)$, both becoming a new source for ethanol. Ethanol use of corn is increased from $\left(Q^{2}-Q^{1}\right)$ to $\left(Q^{2, \text { new }}-Q^{1, \text { new }}\right)$ at the higher corn price.

Denoting the demand for other crop as $Q_{o}^{D}(\boldsymbol{p})$, we can then write the equilibrium conditions in commodity markets as

$$
\begin{gathered}
Q_{c}^{S}(\boldsymbol{p})-Q_{c}^{f D}(\boldsymbol{p})=Q_{c}^{e D}\left(p_{c}\right), \\
Q_{o}^{S}(\boldsymbol{p})-Q_{o}^{D}(\boldsymbol{p})=0 .
\end{gathered}
$$

For any given prices, $\boldsymbol{p}$, the supply of commodities and the demand of commodities as food sources are given. However, for any corn price satisfying the equality condition in $(10), Q_{c}^{e D}\left(p_{c}\right)$ can be any positive number. Thus, $Q_{c}^{e D}\left(p_{c}\right)$ can be considered a residue of the corn market. There are essentially three variables in (11)-(12) that have to be determined: $p_{c}, p_{o}$, and $Q_{c}^{e D}\left(p_{c}\right)$. If one of these variables is known, then we can solve for the other two.

\subsection{System equilibrium and government policies}

A system equilibrium is defined by a set of prices and quantities that satisfy the equilibrium conditions (3), (4), (6), (9), (11), and (12). We assume that the system has a unique stable equilibrium, meaning that after a temporary shock, interactions in the system will cause it to adjust and converge back to its initial equilibrium when the shock is removed. At system equilibrium, total production equals total use for ethanol and each crop; total cropland area equals the sum of production areas of corn and other crop; and net return from agricultural production equals zero for cropland of the lowest quality. In the absence of policy intervention, the corn price will be determined by the ethanol price through (9), and we then can solve for the 
system equilibrium as follows. First, plug $p_{c}$ into (12) to derive the equilibrium $p_{o}$. Then, plug both $p_{c}$ and $p_{o}$ into (11) to derive the equilibrium quantity of corn for ethanol. The prices will also determine the equilibrium land share, input use, and total cropland area through (3), (4), and (6).

If the government provides a subsidy for every unit of ethanol produced, then the corn price is still exogenously determined, though it would be higher than without the subsidy. The system equilibrium in this case can be solved in a way similar to that described in the previous paragraph. Alternatively, suppose that the government sets a mandate that constrains ethanol production either as the maximum or minimum amount of ethanol allowed. An example is the ethanol mandates stipulated in EISA, which sets a series of (minimum) quantities of corn ethanol that have to be met in the coming years. If a mandate is not binding, then the system will reach an equilibrium as if there were no mandate. However, if a mandate is binding, then $p_{c}$ will not be determined by the equality condition in (10), which will no longer necessarily hold. For a fixed $Q_{c}^{e D}$, crop prices and land use variables are simultaneously determined by other equilibrium conditions.

\section{Assessing land use impacts of a change in crop prices}

As mentioned in the introduction, direct land use changes are generally defined as those directly associated with the production of corn used for ethanol while indirect land use changes are any other changes related to land use. Obviously, ethanol draws corn from both new and old corn production fields, with "old" meaning the situation before ethanol expansion. Similarly, some corn produced on newly converted cropland is used as animal feed. In one extreme though unlikely case, corn produced on all new cornfields could be used as animal feed whereas ethanol could draw corn from existing production. Thus, we really have to track ethanol corn back to its production field in order to identify direct land use changes. 
Alternatively, we can consider direct land use changes as newly added corn production area that can come from two sources: cropland originally devoted to other crop, and newly added cropland. These sources are represented by changes in $\alpha_{i}^{*}(\boldsymbol{p} ; \theta)$ and $\theta^{*}(\boldsymbol{p})$, respectively. Even viewed this way, the distinction between indirect and direct land use change is not clear. Part of the newly added cropland will often be used for the other crop and therefore will not be considered as a direct land use change. However, this change in land use is obviously determined by the same market forces as the part devoted to corn production. For these reasons, our analysis will just focus on overall land use changes without distinguishing between direct and indirect changes.

\subsection{Impacts of a price change on land allocation and input decisions}

From Section 2.4, we know that total cropland area, land share, input use, and commodity prices are all jointly determined. However, for the sake of exposition, we can think sequentially as follows. First, total cropland area, land share, and input use are determined through (3), (4), and (6) for any given commodity prices. Then, commodity prices are determined through (9), (11), and (12). In light of this logic, we first examine how land use is affected by commodity prices and then incorporate equilibrium price adjustments into the analysis. From (3) and (4), we can obtain the following (all proofs are given in the Appendix):

$\underline{\operatorname{Remark} 1 .}$ For $i, j=c$ or $o$ and $j \neq i$, given $y_{i}^{z_{i} \alpha_{i}}>0$, we have $\frac{\partial \alpha_{i}^{*}(\boldsymbol{p} ; \theta)}{\partial p_{i}}>0 ; \frac{\partial \alpha_{i}^{*}(\boldsymbol{p} ; \theta)}{\partial p_{j}}<0$; $\frac{\partial z_{i}^{*}(\boldsymbol{p} ; \theta)}{\partial p_{i}}>0 ; \frac{\partial z_{i}^{*}(\boldsymbol{p} ; \theta)}{\partial p_{j}}<0$

In plain words, given $y_{i}^{z_{i} \alpha_{i}}>0$, Remark 1 says that, ceteris paribus, both land share and input use of crop $i$ increase with the price of crop $i$ but decrease with the price of other crop. The condition $y_{i}^{z_{i} \alpha_{i}}>0$ means that, for any given crop, marginal productivity of input is higher 
for higher land share. Using corn as one example, suppose a higher $\alpha_{c}$ means more corn is in continuous corn production. Then we have $y_{c}^{z_{c} \alpha_{c}}>0$ if corn yield function shifts right and down as more production shifts from rotational corn to continuous corn production (see Figure 2 for an illustration). This is consistent with the agronomic observation that continuous corn production requires more input and has lower yields.

Similarly, we can derive the impact on total cropland area as follows:

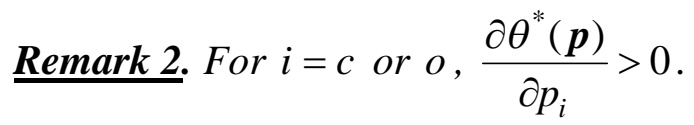

That is, ceteris paribus, total cropland area increases with commodity prices. Note that total cropland area at the initial equilibrium equals $\int_{0}^{\theta^{*}} u(\theta) d \theta$. As more land is brought into agricultural production, the change in cropland area is equal to $\int_{\theta^{*}}^{\theta^{*}+\Delta \theta^{*}} u(\theta) d \theta$, where $\Delta \theta^{*}$ is the change in the quality of marginal cropland. Being a probability distribution function, $u(\theta)$ is always nonnegative. Thus, changes in total cropland area are (weakly) increasing in changes in the quality of marginal land. For most of our discussion, we examine the change in total cropland area by examining changes in $\theta^{*}$.

\subsection{Impacts of a price change on crop supply}

Land allocation and input use adjustments in response to changes in crop prices will be translated into changes in crop supply. Differentiating (7) with respect to $p_{j}$, we have for any $i, j=c$ or $o$,

$$
\begin{aligned}
& \frac{\partial Q_{i}^{S}(\boldsymbol{p})}{\partial p_{j}}=\left.\frac{\partial Q_{i}^{S}}{\partial p_{j}}\right|_{\theta}+\left.\frac{\partial Q_{i}^{S}}{\partial p_{j}}\right|_{\alpha_{i}}+\left.\frac{\partial Q_{i}^{S}}{\partial p_{j}}\right|_{z_{i}}, \text { where } \\
& \left.\frac{\partial Q_{i}^{S}}{\partial p_{j}}\right|_{\theta} \equiv y_{i}^{*}\left(z_{i}^{*}, \alpha_{i}^{*} ; \theta^{*}\right) \alpha_{i}^{*}\left(\boldsymbol{p} ; \theta^{*}\right) \frac{\partial \theta^{*}(\boldsymbol{p})}{\partial p_{j}} u\left(\theta^{*}\right)
\end{aligned}
$$

(total land effect) 


$$
\begin{aligned}
& \left.\frac{\partial Q_{i}^{S}}{\partial p_{j}}\right|_{\alpha_{i}} \equiv \int_{0}^{\theta^{*}}\left(y_{i}^{*}\left(z_{i}^{*}, \alpha_{i}^{*} ; \theta\right)+y_{i}^{\alpha_{i}^{*}}\left(z_{i}^{*}, \alpha_{i}^{*} ; \theta\right) \alpha_{i}^{*}(\boldsymbol{p} ; \theta)\right) \frac{\partial \alpha_{i}^{*}(\boldsymbol{p} ; \theta)}{\partial p_{j}} u(\theta) d \theta \quad \text { (land share effect) } \\
& \left.\frac{\partial Q_{i}^{S}}{\partial p_{j}}\right|_{z_{i}} \equiv \int_{0}^{\theta^{*}} y_{i}^{z_{i}^{*}}\left(z_{i}^{*}, \alpha_{i}^{*} ; \theta\right) \alpha_{i}^{*}(\boldsymbol{p} ; \theta) \frac{\partial z_{i}^{*}(\boldsymbol{p} ; \theta)}{\partial p_{j}} u(\theta) d \theta . \quad \text { (input use effect). }
\end{aligned}
$$

The three effects, as defined in (13), are basically those examined in Remarks 1 and 2.

According to these remarks, land share effect and input use effect have the same sign, which is not necessarily the same as the sign of total land effect. For ease of reference, we define the following conditions.

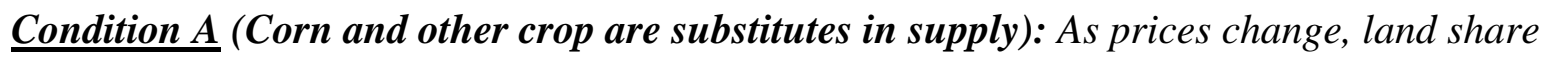
effect and input use effect dominate the total land effect, i.e., the sum of $\left.\frac{\partial Q_{i}^{S}}{\partial p_{j}}\right|_{\alpha_{i}}$ and $\left.\frac{\partial Q_{i}^{S}}{\partial p_{j}}\right|_{z_{i}}$ is greater than $\left.\frac{\partial Q_{i}^{S}}{\partial p_{j}}\right|_{\theta}$ in absolute value. Or equivalently, $\frac{\partial Q_{i}^{S}(\boldsymbol{p})}{\partial p_{j}}<0$ for $j \neq i$.

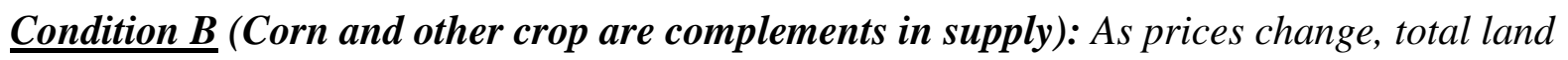
effect weakly dominates land share effect and input use effect, i.e., $\left.\frac{\partial Q_{i}^{S}}{\partial p_{j}}\right|_{\theta}$ is greater than or equal to the sum of $\left.\frac{\partial Q_{i}^{S}}{\partial p_{j}}\right|_{\alpha_{i}}$ and $\left.\frac{\partial Q_{i}^{S}}{\partial p_{j}}\right|_{z_{i}}$ in absolute value. Or equivalently, $\frac{\partial Q_{i}^{S}(\boldsymbol{p})}{\partial p_{j}} \geq 0$ for $j \neq i$. For example, when $p_{c}$ increases, all three effects are positive for $Q_{c}^{S}(\boldsymbol{p})$, implying that the corn supply increases (moving along the corn supply curve). For $Q_{o}^{S}(\boldsymbol{p})$, the land share effect and the input use effect will be negative while the total land effect will be positive. Under Condition A, the overall effect takes the negative sign of the land share and input use effect, implying a leftward shift of the supply curve for other crop. Under Condition B, the overall 
effect takes the positive sign of the total land effect, implying a rightward shift of the supply curve for other crop. In summary, we have the following.

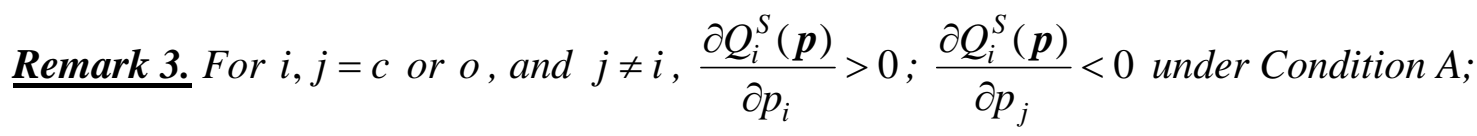

$\frac{\partial Q_{i}^{S}(\boldsymbol{p})}{\partial p_{j}} \geq 0$ under Condition $B$

The competition for land makes corn and other crop likely substitutes in supply, while the need for rotation makes them likely complements in supply. Whether corn and other crop are substitutes or complements in supply depends on which of these forces is stronger.

\section{Land use impacts at market equilibrium}

Our objective is to examine how land use responds to changes in ethanol production. In Remarks 1 and 2, the results on land share, input use, and total cropland area are derived with respect to a change in one crop price; the price of other crop is held constant. To assess land use impacts at market equilibrium, we need to take into account how changes in one crop will lead to changes in the price of other crops.

\subsection{Land use impacts without government intervention}

For a given corn price, (12) determines the price of other crop. Totally differentiating (12) with respect to prices and rearranging, we obtain

$$
\begin{gathered}
\frac{d p_{o}\left(p_{c}\right)}{d p_{c}} \frac{p_{c}}{p_{o}}=-\frac{p_{c}}{p_{o}}\left[\frac{\partial Q_{o}^{D}(\boldsymbol{p})}{\partial p_{c}}-\frac{\partial Q_{o}^{S}(\boldsymbol{p})}{\partial p_{c}}\right]\left[\frac{\partial Q_{o}^{D}(\boldsymbol{p})}{\partial p_{o}}-\frac{\partial Q_{o}^{S}(\boldsymbol{p})}{\partial p_{o}}\right]^{-1}, \\
=-\left[\varepsilon_{o, p_{c}}^{D}-\varepsilon_{o, p_{c}}^{S}\right]\left[\varepsilon_{o, p_{o}}^{D}-\varepsilon_{o, p_{o}}^{S}\right]^{-1}
\end{gathered}
$$

where $\varepsilon_{i, p_{j}}^{S}$ is the elasticity of the supply of $i$ with respect to $p_{j}$. Other elasticity terms are defined similarly. The terms in the denominator are just the elasticities of demand and the supply 
curve of other crop with respect to own price. The numerator consists of supply and demand elasticities of other crop with respect to the corn price. Given an upward-sloping supply curve and a downward-sloping demand curve, the denominator is negative. From Remark 3 and (14), the following is self-evident: ${ }^{5}$

Proposition 1. If corn and other crop are substitutes in demand, then (i) the price of other crop increases with the price of corn when corn and other crop are substitutes in supply, or when they are complements in supply with $\left(\varepsilon_{o, p_{c}}^{D}-\varepsilon_{o, p_{c}}^{S}\right)>0$; (ii) the price of other crop decreases with the price of corn when corn and other crop are complements in supply with $\left(\varepsilon_{o, p_{c}}^{D}-\varepsilon_{o, p_{c}}^{S}\right) \leq 0$.

Essentially, $\left(\varepsilon_{o, p_{c}}^{D}-\varepsilon_{o, p_{c}}^{S}\right)$ measures the responsiveness of the excess demand of other crop to corn price. The larger this term is, the higher $p_{o}$ will rise. Intuitively, as the corn price increases, corn becomes more profitable relative to other crop, and so corn's land share increases. For stronger land competition, meaning the increase in corn's land share is smaller for the same change in corn price, the supply of other crop will decrease by a smaller degree, i.e., $\varepsilon_{o, p_{c}}^{S}$ is smaller in magnitude. Given the smaller shift in supply, ceteris paribus, the increase in the price of other crop is also smaller. Similarly, if $\varepsilon_{o, p_{c}}^{D}$ is smaller, the demand for other crop will increase by a smaller degree, reducing the upward pressure on the price of other crop. This will also lead to a smaller increase in the price of other crop. In a special case, if the market for other crop is independent of the corn market (i.e., no substitution or complementary effect in demand and supply), then $\left(\varepsilon_{o, p_{c}}^{D}-\varepsilon_{o, p_{c}}^{S}\right)=0$ and there will be no adjustment in the price of other crop as the corn price changes.

Responses in total cropland area are especially important for greenhouse gases and other environmental factors because more cropland means less grassland or forestland, which is

\footnotetext{
${ }^{5}$ We consider only the case that corn and other crop are substitutes in demand because corn and other crops (as a composite) can substitute for one another to some degree as a food source.
} 
usually much more environmental friendly than cropland. By contrast, relatively speaking, a shift of cropland from one crop to another or a change in input use tends to have smaller environmental consequences. Thus, next we will focus on a change in total cropland area. First, we can express adjustments in total cropland area as

$$
\frac{d \theta^{*}(\boldsymbol{p})}{d p_{c}}=\frac{\partial \theta^{*}(\boldsymbol{p})}{\partial p_{c}}+\frac{\partial \theta^{*}(\boldsymbol{p})}{\partial p_{o}} \frac{d p_{o}\left(p_{c}\right)}{d p_{c}}
$$

Change in total cropland area is the sum of the two effects of higher corn prices: the direct effect and the indirect effect that acts through changes in the price of other crop. Remark 2 shows that $\frac{\partial \theta^{*}(\boldsymbol{p})}{\partial p_{i}}>0$. Thus, the sign of $\frac{d \theta^{*}(\boldsymbol{p})}{d p_{c}}$ depends on the indirect effect through $p_{o}$.

Proposition 2. When the corn price is set equal to the breakeven price in ethanol production, if corn and other crop are substitutes in demand, then total cropland area increases with the corn price at market equilibrium regardless of corn and other crop being substitutes or complements in supply.

Intuitively, an increase in $p_{c}$ enhances the profitability of cropland making it profitable to bring poorer quality land into agricultural production. If corn and other crop are substitutes in both supply and demand, then higher $p_{c}$ means less supply and more demand for other crop resulting a higher price for other crop. Total cropland expands as farming becomes more profitable with higher prices for all crops. If corn and other crop are complements in supply, then more land devoted to corn requires more land devoted to other crop as well. Thus, higher $p_{c}$ results in more land for both corn and other crop, indicating increased total cropland area. Note that such cropland expansion can cause the price of other crop to fall.

\subsection{Land use impacts of ethanol subsidies}

Price subsidies for ethanol are equivalent to increases in the ethanol price for ethanol producers. From (9), it is clear that such subsidies will increase the breakeven corn price in ethanol 
production. Thus, we can assess the land use impacts of subsidies by looking at the impacts of higher corn prices, which are examined in the preceding subsection.

\subsection{Land use impacts of ethanol mandates}

Let $\tilde{Q}_{c}^{e}$ be the quantity mandate for ethanol expressed in terms of the quantity of corn required. Given such a mandate, the corn price is no longer determined by the long-term breakeven price in ethanol production. Instead, it will be jointly determined by (11) and (12) with ethanol quantity fixed at $\tilde{Q}_{c}^{e}$.

Proposition 3. If corn and other crop are substitutes in demand, then total cropland area increases with an ethanol mandate.

The response in total cropland area depends on how crop prices respond to higher demand for corn arising from a higher ethanol mandate. A higher demand for corn will lead to a higher corn price. Whether corn and other crop are substitutes or complements in supply, total cropland area increases, as shown in Proposition 2.

\subsection{Land use impacts of higher yields without government intervention}

We are particularly interested in how yield improvement affects the equilibrium land use. Before turning to this question, we need be clear as to the exact meaning of "yield improvement" given that yield is a function of input use, land share, and land quality.

Definition 1. Let "new" and "old" represent two yield varieties of crop i. By "yield improvement" for crop i, we mean either (i) or (ii) below.

(i) Yields of crop $i$ shift up by a constant, i.e., for a given $\delta_{i}>0$, $y_{i}^{\text {new }}\left(z_{i}, \alpha_{i} ; \delta_{i}, \theta\right)=y_{i}^{\text {old }}\left(z_{i}, \alpha_{i} ; \theta\right)+\delta_{i}$ holds for any $z_{i} \geq 0, \alpha_{i} \in[0,1]$, and $\theta \in[0,1]$;

(ii) Yields of crop $i$ shift up proportionately, i.e., for a given $\psi_{i}>1$, $y_{i}^{\text {new }}\left(z_{i}, \alpha_{i} ; \psi_{i}, \theta\right)=\psi_{i} y_{i}^{\text {old }}\left(z_{i}, \alpha_{i} ; \theta\right)$ holds for any $z_{i} \geq 0, \alpha_{i} \in[0,1]$, and $\theta \in[0,1]$. 
When yields shift up by a constant, marginal yields do not change; only the magnitude of yields increases. By contrast, when yields shift up proportionately, both yields and marginal yields increase. In addition to directly changing crop output, an exogenously given yield shock (a change in $\delta_{i}$ or $\psi_{i}$ ) will change crop output through adjustments in optimal land share, input use, and total cropland area. At market equilibrium, we can show the following:

Proposition 4. When the corn price is set equal to the breakeven price in ethanol production, total cropland area increases with (i) yield improvement for corn; and (ii) yield improvement for other crop, if $\varepsilon_{p_{o}, \delta_{o}}>-1$.

Yield improvement enhances the profitability of corn, increasing net returns to land for any given land allocation. Thus, land of poorer quality will be drawn into production with a higher corn yield. Yield improvement for other crop would have the same effects except for one difference. Corn prices are determined by ethanol prices and so are not affected by changes in corn supply. By contrast, an increased supply of other crop can reduce its price in equilibrium, relieving the pressure for cropland expansion. The overall impacts of yield increases for other crop depend on how responsive its price is to changes in its supply due to higher yields. If its price does not drop too much, then total cropland area will increase.

\subsection{Land use impacts of higher yields under ethanol mandates}

The impacts of higher yields under an ethanol mandate are similar to those in crop supply and demand models without the mandate. The only difference is that instead of maintaining a zero difference between corn supply and demand, here we need to guarantee that the difference is a positive constant. How supply responds to higher yields and how demand and crop prices adjust will be exactly the same as in crop models without ethanol mandates.

Proposition 5. Under a given mandate, higher yields for either corn or other crop will result in (i) more total cropland area if crop demand is perfectly elastic, and (ii) less total cropland area if crop demand is perfectly inelastic and land share and input use move in the same direction. 
Remark 1 indicates that, ceteris paribus, land share and input use move in the same direction for a change in the price of any crop. The condition at the end of the above proposition requires that, when all crop prices are allowed to adjust, they will still move in the same direction. With continuity, we can conclude the following:

Remark 4. Under a given ethanol mandate, higher yields for either corn or other crop will result in (i) more total cropland area if crop demand is elastic enough, and (ii) less total cropland area if the crop demand is inelastic enough and land share and input use move in the same direction.

Intuitively, productivity increases will increase crop supply if nothing else changes. For any given amount of corn that has to be set aside to meet the requirement of an ethanol mandate, this will put downward pressure on crop prices. How much crop prices change is crucial to determining total cropland area. With a binding mandate that caps ethanol production, all the increased corn supply will be devoted to food production. Given that food demand is inelastic, yield increases under this type of mandate will reduce land use. This is in contrast to today's ethanol policy that has created a floor mandate. With a floor, total demand for corn is likely quite elastic, implying that total cropland is likely to expand.

\section{Concluding remarks}

In this paper, we have developed a straightforward economic framework to assess the land use impacts of biofuels. We analyzed land use changes of ethanol expansion given adjustments in acreage allocation between crops, the quality and availability of additional land for crop production, agricultural crop markets, and ethanol production. When agricultural crops are converted to transportation fuels, a direct link is created between crop markets and crude oil markets. Without government intervention, this means that higher crude oil prices will result in higher corn prices. Until recently, at relatively low crude oil prices, the biofuel industry has largely depended on the government for development or even survival. If crude oil prices persistently stand at over $\$ 120$ a barrel, then the biofuel industry can expand without government 
support. Such expansion will lead to more land being converted to cropland because more biofuel production means higher demand for agricultural crops, which in turn means higher net return to cropland. In such situations, government intervention would be needed to prevent the loss of forest and grass land.

Our simple framework can assist the understanding of some of the most basic issues related to land use and biofuels. For example, upon careful examination, we show that the distinction between direct and indirect land use changes seems to be much less obvious than commonly assumed. Somewhat counter-intuitively, higher yields will not necessarily relieve the pressure on cropland expansion as many have argued or hoped. If anything, under free market conditions, higher yields for a crop that is used for biofuels will lead to even more land going into agricultural production. This is because higher yields mean higher profits on a given acre, unless output prices decrease dramatically. If biofuels account for only a small percentage of transportation fuel, as they do now, a greater supply of biofuels will not significantly depress fuel prices, which in turn implies that crop prices will not decrease significantly. However, higher yields can lead to a reduction in cropland area if government mandates act as a ceiling of allowed biofuels. The intuition is that with higher yields, less area is needed to supply the world's need for food and (a fixed quantity of) biofuels. 
Figure 1. Corn market ( $p_{c}$ is the breakeven corn price for ethanol production)

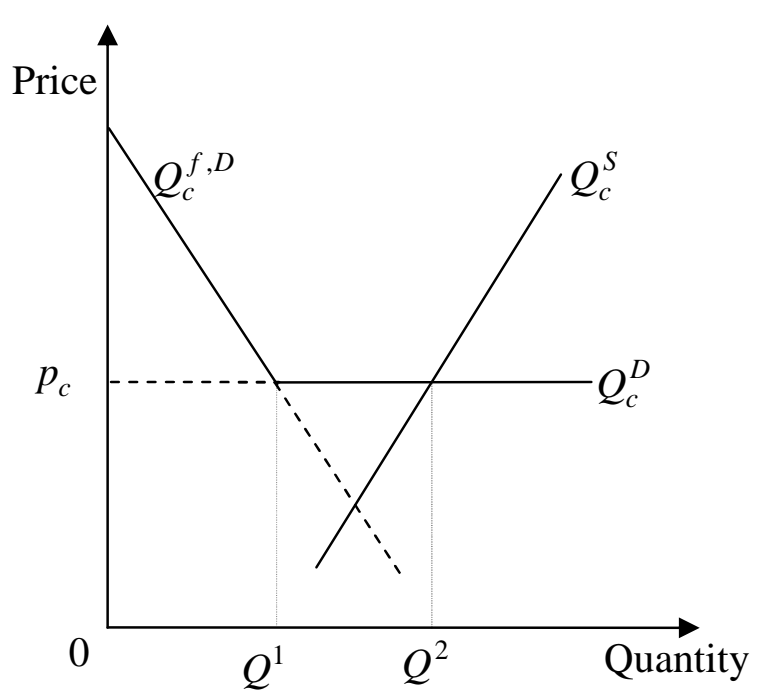

A. Total corn demand with supply

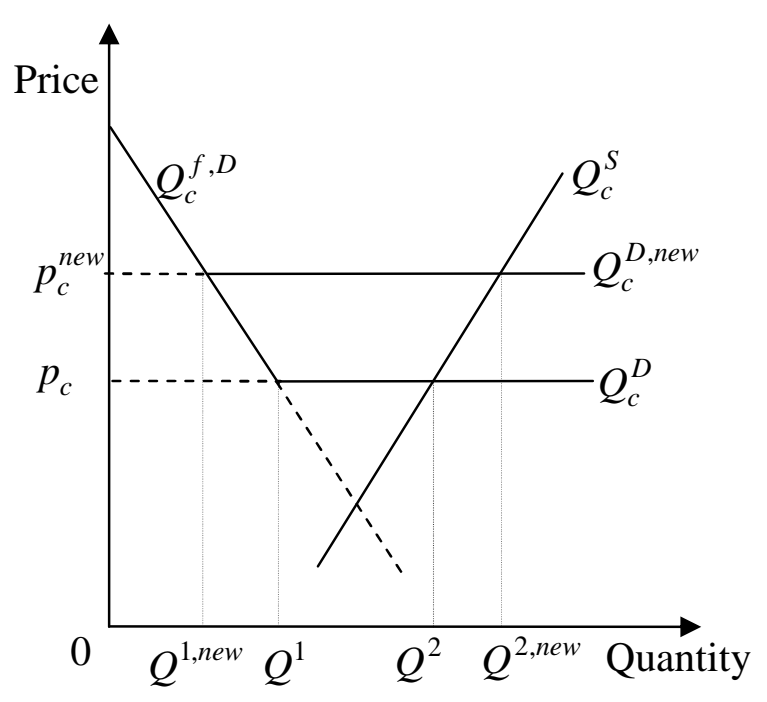

B. Effects of higher $p_{c}$

Figure 2. Yield as a function of input use given different land share

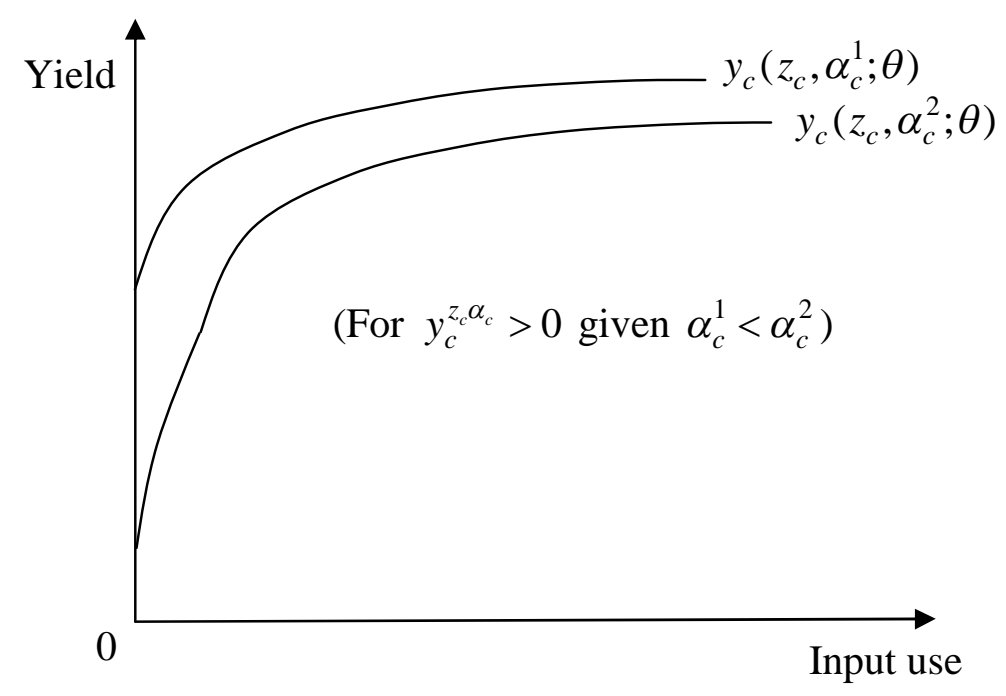




\section{Appendix}

Proof of Remark 1. The results are derived through comparative statics for the problem in (2). Substituting out $\alpha_{o}(\theta)$ with $\alpha_{o}(\theta)=1-\alpha_{c}(\theta)$, then problem (2) is basically an unconstrained optimization problem in $\alpha_{c}(\theta), z_{c}(\theta)$ and $z_{o}(\theta)$ for interior solutions. First, note that ${ }^{6}$

$$
\begin{gathered}
\pi^{\alpha_{c} \alpha_{c}}=\left(2 p_{c} y_{c}^{\alpha_{c}}+p_{c} \alpha_{c} y_{c}^{\alpha_{c} \alpha_{c}}\right)+\left(2 p_{o} y_{o}^{\alpha_{o}}+p_{o} \alpha_{o} y_{o}^{\alpha_{o} \alpha_{o}}\right) \\
\pi^{z_{i} z_{i}}=\alpha_{i} p_{i} y_{i}^{z_{i} z_{i}} \\
\pi^{z_{c} \alpha_{c}}=\pi^{\alpha_{c} z_{c}}=\alpha_{c} p_{c} y_{c}^{z_{c} \alpha_{c}} \\
\pi^{z_{o} \alpha_{c}}=\pi^{\alpha_{c} z_{o}}=-\alpha_{o} p_{o} y_{o}^{z_{o} \alpha_{o}}
\end{gathered}
$$

Given $y_{i}^{\alpha_{i} z_{i}}>0$, we have $\pi^{z_{c} \alpha_{c}}>0$ and $\pi^{z_{o} \alpha_{c}}<0$. Let $H$ be the determinant of the Hessian of the problem in (2) with the three decision variables, $\alpha_{c}(\theta), z_{c}(\theta)$ and $z_{o}(\theta)$. The second-order sufficient condition requires that $\pi^{\alpha_{c} \alpha_{c}}<0, \pi^{z_{i} z_{i}}<0$, and $H<0$. Then, we obtain

$$
\frac{\partial \alpha_{c}^{*}(\boldsymbol{p} ; \theta)}{\partial p_{c}}=-\pi^{z_{o} z_{o}}\left[\left(y_{c}+\alpha_{c} y_{c}^{\alpha_{c}}\right) \pi^{z_{c} z_{c}}-\alpha_{c} y_{c}^{z_{c}} \pi^{z_{c} \alpha_{c}}\right] H^{-1}>0
$$

The variables on the right-hand side of (20) are all evaluated at the optimal; however, to avoid cluster, we avoid using " $*$ " to indicate this. Note that $y_{c}+\alpha_{c} y_{c}^{\alpha_{c}}>0$ is implied by (3); otherwise, the marginal profit with respect to corn land share is negative, making it optimal to reduce $\alpha_{c}$.

Similarly, we can obtain

$$
\frac{\partial \alpha_{c}^{*}(\boldsymbol{p} ; \theta)}{\partial p_{o}}=\pi^{z_{c} z_{c}}\left[\left(y_{o}+\alpha_{o} y_{o}^{\alpha_{o}}\right) \pi^{z_{o} z_{o}}+\alpha_{o} y_{o}^{z_{o}} \pi^{z_{o} \alpha_{c}}\right] H^{-1}<0
$$

Or equivalently, $\frac{\partial \alpha_{o}^{*}(\boldsymbol{p} ; \theta)}{\partial p_{o}}>0$. As to the input use decision, we can obtain

\footnotetext{
${ }^{6}$ To simplify notation, we drop $u(\theta)$ in the following proofs. Keeping $u(\theta)$ in the derivatives of $\pi(z, \alpha ; \theta)$ makes no essential difference to the proofs.
} 


$$
\frac{\partial z_{c}^{*}(\boldsymbol{p} ; \theta)}{\partial p_{c}}=-\alpha_{c} y_{c}^{z_{c}}\left[\pi^{\alpha_{c} \alpha_{c}} \pi^{z_{o} z_{o}}-\left(\pi^{z_{0} \alpha_{c}}\right)^{2}\right] H^{-1}+\left[\left(y_{c}+\alpha_{c} y_{c}^{\alpha_{c}}\right) \pi^{z_{o} z_{o}} \pi^{z_{c} \alpha_{c}}\right] H^{-1}>0
$$

In signing the above derivative, we used $\left[\pi^{\alpha_{c} \alpha_{c}} \pi^{z_{o} z_{o}}-\left(\pi^{z_{0} \alpha_{c}}\right)^{2}\right]>0$, which is required by the second-order sufficient condition for the problem in (2).

$$
\begin{aligned}
& \frac{\partial z_{o}^{*}(\boldsymbol{p} ; \theta)}{\partial p_{c}}=\pi^{z_{o} \alpha_{c}}\left[-\alpha_{c} y_{c}^{z_{c}} \pi^{z_{c} \alpha_{c}}+\left(y_{c}+\alpha_{c} y_{c}^{\alpha_{c}}\right) \pi^{z_{c} z_{c}}\right] H^{-1}<0 \\
& \frac{\partial z_{c}^{*}(\boldsymbol{p} ; \theta)}{\partial p_{o}}=\pi^{z_{c} \alpha_{c}}\left[-\alpha_{o} y_{o}^{z_{o}} \pi^{z_{o} \alpha_{c}}-\left(y_{o}+\alpha_{o} y_{o}^{\alpha_{o}}\right) \pi^{z_{o} z_{o}}\right] H^{-1}<0
\end{aligned}
$$

$$
\frac{\partial z_{o}^{*}(\boldsymbol{p} ; \theta)}{\partial p_{o}}=-\alpha_{o} y_{o}^{z_{o}}\left[\pi^{\alpha_{c} \alpha_{c}} \pi^{z_{c} z_{c}}-\left(\pi^{z_{c} \alpha_{c}}\right)^{2}\right] H^{-1}-\left[\left(y_{o}+\alpha_{o} y_{o}^{\alpha_{o}}\right) \pi^{z_{c} z_{c}} \pi^{z_{o} \alpha_{c}}\right] H^{-1}>0
$$

Proof of Remark 2. Differentiating (6) with respect to prices and rearranging, we obtain (also see footnote 6)

$$
\frac{\partial \theta^{*}(\boldsymbol{p})}{\partial p_{i}}=-\alpha_{i} y_{i}\left(\pi^{\theta}\right)^{-1}=-\alpha_{i} y_{i}\left(\sum_{j=c, o}\left[p_{j} y_{j}^{\theta}\left(z_{j}, \alpha_{j} ; \theta\right) \alpha_{j}\right]\right)^{-1}>0
$$

Proof of Proposition 2. From Remark 2, we know that $\frac{\partial \theta^{*}(\boldsymbol{p})}{\partial p_{c}}>0$ and $\frac{\partial \theta^{*}(\boldsymbol{p})}{\partial p_{o}}>0$. Then, (15) indicates that our first task is to see if $\frac{d p_{o}\left(p_{c}\right)}{d p_{c}}>0$. Based on Proposition $1, \frac{d p_{o}\left(p_{c}\right)}{d p_{c}}>0$ under Condition A or Condition B with $\left(\varepsilon_{o, p_{c}}^{D}-\varepsilon_{o, p_{c}}^{S}\right)>0$. Thus, $\frac{d \theta^{*}\left(p_{c}\right)}{d p_{c}}>0$ under these conditions. When $\frac{d p_{o}\left(p_{c}\right)}{d p_{c}} \leq 0$, the proof is less obvious since the right-hand side of (15) is then the sum of two parts with opposite signs. Thus, we pursue the proof in an alternative way. Note that

$$
\frac{d \alpha_{c}^{*}\left(p_{c} ; \theta\right)}{d p_{c}}=\frac{\partial \alpha_{c}^{*}(\boldsymbol{p} ; \theta)}{\partial p_{c}}+\frac{\partial \alpha_{c}^{*}(\boldsymbol{p} ; \theta)}{\partial p_{o}} \frac{d p_{o}\left(p_{c}\right)}{d p_{c}}
$$


Therefore, $\frac{d \alpha_{c}^{*}\left(p_{c} ; \theta\right)}{d p_{c}}>0$, or equivalently, $\frac{d \alpha_{o}^{*}\left(p_{c} ; \theta\right)}{d p_{c}}<0$, for $\frac{d p_{o}\left(p_{c}\right)}{d p_{c}} \leq 0$. Similarly, we can show that $\frac{d z_{o}^{*}\left(p_{c} ; \theta\right)}{d p_{c}}<0$ for $\frac{d p_{o}\left(p_{c}\right)}{d p_{c}} \leq 0$. Meanwhile, $\frac{d p_{o}\left(p_{c}\right)}{d p_{c}} \leq 0$ implies increased total consumption of other crop as the corn price increases. This is because, when corn and other crop are substitutes in demand, for $p_{o}^{\text {new }} \leq p_{o}^{\text {old }}$ and $p_{c}^{\text {new }} \geq p_{c}^{\text {old }}$, we must have $Q_{o}^{D}\left(p_{o}^{\text {new }}, p_{c}^{\text {new }}\right)$ $\geq Q_{o}^{D}\left(p_{o}^{\text {new }}, p_{c}^{\text {old }}\right) \geq Q_{o}^{D}\left(p_{o}^{\text {old }}, p_{c}^{\text {old }}\right)$. The superscripts "old" and "new" represent the situation before and after the rise in $p_{c}$, respectively. Increased consumption can occur with decreased land share and input use only if total cropland area has increased, i.e., $\frac{d \theta^{*}\left(p_{c}\right)}{d p_{c}}>0$.

Proof of Proposition 3. Under a mandate, $Q_{c}^{e D}\left(p_{c}\right)$ is a constant fixed by policymakers, denoted as $\tilde{Q}_{c}^{e}$. Totally differentiate (11)-(12) with respect to $\tilde{Q}_{c}^{e}$ and then solve to obtain

$$
\frac{d p_{c}\left(\tilde{Q}_{c}^{e}\right)}{d \tilde{Q}_{c}^{e}}=-\left(\frac{\partial Q_{o}^{D}}{\partial p_{o}}-\frac{\partial Q_{o}^{S}}{\partial p_{o}}\right) M^{-1}, \quad \frac{d p_{o}\left(\tilde{Q}_{c}^{e}\right)}{d \tilde{Q}_{c}^{e}}=\left(\frac{\partial Q_{o}^{D}}{\partial p_{c}}-\frac{\partial Q_{o}^{S}}{\partial p_{c}}\right) M^{-1},
$$

where $M \equiv\left(\frac{\partial Q_{c}^{f D}}{\partial p_{c}}-\frac{\partial Q_{c}^{S}}{\partial p_{c}}\right)\left(\frac{\partial Q_{o}^{D}}{\partial p_{o}}-\frac{\partial Q_{o}^{S}}{\partial p_{o}}\right)-\left(\frac{\partial Q_{o}^{D}}{\partial p_{c}}-\frac{\partial Q_{o}^{S}}{\partial p_{c}}\right)\left(\frac{\partial Q_{c}^{f D}}{\partial p_{o}}-\frac{\partial Q_{c}^{S}}{\partial p_{o}}\right)$. The first two pairs of parentheses of $M$ indicate the responses of excess demand with respect to own prices, while the last two pairs of parentheses are the responses to changes in the price of other crop. If excess demand of a crop is more sensitive to a change in the price of that crop than it is to a price change of the other crop, then $M$ is positive. For the system to have a stable equilibrium, $M$ must be positive (Arrow et al., Negishi). This means that $\frac{d p_{c}\left(\tilde{Q}_{c}^{e}\right)}{d \tilde{Q}_{c}^{e}}$ is positive, and $\frac{d p_{o}\left(\tilde{Q}_{c}^{e}\right)}{d \tilde{Q}_{c}^{e}}$ is also positive if corn and other crop are substitutes in supply and demand. If corn and other crop 
are complements in supply, $\frac{d p_{o}\left(\tilde{Q}_{c}^{e}\right)}{d \tilde{Q}_{c}^{e}}>0$ still holds if $\left(\varepsilon_{o, p_{c}}^{D}-\varepsilon_{o, p_{c}}^{S}\right)>0$. Otherwise,

$\frac{d p_{o}\left(\tilde{Q}_{c}^{e}\right)}{d \tilde{Q}_{c}^{e}} \leq 0$. In this case, we have higher $p_{c}$ and lower $p_{o}$ in the new equilibrium. In the proof of Proposition 2, we have shown that such price changes imply increased total cropland area.

Proof of Proposition 4. We first obtain how input use, land share, and total cropland area changes with yield improvement holding commodity prices constant. Then we incorporate price responses at the new equilibrium. The two types of yield improvement as defined in Definition 1 are considered separately. However, given the similarity of the proof, we present the proof for only the case in which yields of crop $i$ shift up by a constant, $\delta_{i}$. Differentiating (6) with respect to $\delta_{i}$ and rearranging, we obtain (also see footnote 6)

$$
\frac{\partial \theta^{*}(\boldsymbol{p} ; \boldsymbol{\delta})}{\partial \delta_{i}}=-\alpha_{i} p_{i}\left(\pi^{\theta}\right)^{-1}=-\alpha_{i} p_{i}\left(\sum_{j=c, o}\left[p_{j} y_{j}^{\theta}\left(z_{j}, \alpha_{j} ; \delta_{j}, \theta\right) \alpha_{j}\right]\right)^{-1}>0
$$

Thus, total cropland area increases upon yield improvement of any crop for given commodity prices. Differentiate (3)-(4) with respect to $\delta_{i}$ and then solve to obtain

$$
\begin{gathered}
\frac{\partial \alpha_{c}^{*}(\boldsymbol{p} ; \boldsymbol{\delta}, \theta)}{\partial \delta_{c}}=-p_{c} \pi^{z_{c} z_{c}} \pi^{z_{o} z_{o}} H^{-1}>0, \\
\frac{\partial \alpha_{c}^{*}(\boldsymbol{p} ; \boldsymbol{\delta}, \theta)}{\partial \delta_{o}}=p_{o} \pi^{z_{c} z_{c}} \pi^{z_{o} z_{o}} H^{-1}<0, \\
\frac{\partial z_{c}^{*}(\boldsymbol{p} ; \boldsymbol{\delta}, \theta)}{\partial \delta_{c}}=p_{c} \pi^{\alpha_{c} z_{c}} \pi^{z_{o} z_{o}} H^{-1}>0, \\
\frac{\partial z_{c}^{*}(\boldsymbol{p} ; \boldsymbol{\delta}, \theta)}{\partial \delta_{o}}=-p_{o} \pi^{\alpha_{c} z_{c}} \pi^{z_{o} z_{o}} H^{-1}<0, \\
\frac{\partial z_{o}^{*}(\boldsymbol{p} ; \boldsymbol{\delta}, \theta)}{\partial \delta_{c}}=p_{c} \pi^{z_{c} z_{c}} \pi^{z_{o} \alpha_{c}} H^{-1}<0,
\end{gathered}
$$




$$
\frac{\partial z_{o}^{*}(\boldsymbol{p} ; \boldsymbol{\delta}, \theta)}{\partial \delta_{o}}=-p_{o} \pi^{z_{c} z_{c}} \pi^{z_{0} \alpha_{c}} H^{-1}>0
$$

The above adjustments will change the supply of commodities. We can define the three effects on crop supply in the same way as those in (13) except that the derivatives are now taken with respect to yield improvement factors $\left(\delta_{i}\right.$ or $\left.\psi_{i}\right)$, e.g.,

$$
\frac{\partial Q_{i}^{S}(\boldsymbol{p} ; \boldsymbol{\delta})}{\partial \delta_{j}}=\left.\frac{\partial Q_{i}^{S}}{\partial \delta_{j}}\right|_{\theta}+\left.\frac{\partial Q_{i}^{S}}{\partial \delta_{j}}\right|_{\alpha_{i}}+\left.\frac{\partial Q_{i}^{S}}{\partial \delta_{j}}\right|_{z_{i}}+\left.\frac{\partial Q_{i}^{S}}{\partial \delta_{j}}\right|_{\delta_{j}}, \text { where }
$$

$$
\left.\frac{\partial Q_{i}^{S}}{\partial \delta_{j}}\right|_{\theta} \equiv y_{i}^{*}\left(z_{i}^{*}, \alpha_{i}^{*} ; \delta_{i}, \theta^{*}\right) \alpha_{i}^{*}\left(\boldsymbol{p} ; \boldsymbol{\delta}, \theta^{*}\right) \frac{\partial \theta^{*}(\boldsymbol{p} ; \boldsymbol{\delta})}{\partial \delta_{j}} u\left(\theta^{*}\right) \quad \quad \text { (total land effect) }
$$$$
\left.\frac{\partial Q_{i}^{S}}{\partial \delta_{j}}\right|_{\alpha_{i}} \equiv \int_{0}^{\theta^{*}}\left(y_{i}^{*}\left(z_{i}^{*}, \alpha_{i}^{*} ; \delta_{i}, \theta\right)+y_{i}^{\alpha_{i}^{*}} \alpha_{i}^{*}(\boldsymbol{p} ; \boldsymbol{\delta}, \theta)\right) \frac{\partial \alpha_{i}^{*}(\boldsymbol{p} ; \boldsymbol{\delta}, \theta)}{\partial \delta_{j}} u(\theta) d \theta \quad \text { (land share effect) }
$$$$
\left.\frac{\partial Q_{i}^{S}}{\partial \delta_{j}}\right|_{z_{i}} \equiv \int_{0}^{\theta^{*}} y_{i}^{z_{i}^{*}}\left(z_{i}^{*}, \alpha_{i}^{*} ; \delta_{i}, \theta\right) \alpha_{i}^{*}(\boldsymbol{p} ; \boldsymbol{\delta}, \theta) \frac{\partial z_{i}^{*}(\boldsymbol{p} ; \boldsymbol{\delta}, \theta)}{\partial \delta_{j}} u(\theta) d \theta . \quad \text { (input use effect) }
$$

$$
\left.\frac{\partial Q_{i}^{S}}{\partial \delta_{j}}\right|_{\delta_{j}} \equiv \int_{0}^{\theta^{*}} \alpha_{i}^{*}(\theta) u(\theta) d \theta \text { for } j=i,\left.\frac{\partial Q_{i}^{S}}{\partial \delta_{j}}\right|_{\delta_{j}} \equiv 0 \text { for } j \neq i \quad \text { (direct yield effect) }
$$

The last effect is not in (13) because $\delta_{j}$, unlike $p_{j}$, can change crop supply directly. We define the following conditions, which are similar to Conditions A and B.

Condition A'. As yield improves, land share effect and input use effect dominate the total land effect, i.e., the sum of $\left.\frac{\partial Q_{i}^{S}}{\partial \delta_{j}}\right|_{\alpha_{i}}$ and $\left.\frac{\partial Q_{i}^{S}}{\partial \delta_{j}}\right|_{z_{i}}$ is greater than $\left.\frac{\partial Q_{i}^{S}}{\partial \delta_{j}}\right|_{\theta}$ in absolute value. Or equivalently, $\frac{\partial Q_{i}^{S}(\boldsymbol{p} ; \boldsymbol{\delta})}{\partial \delta_{j}}<0$ for $j \neq i$ 
Condition B'. As yield improves, total land effect weakly dominates land share effect and input use effect, i.e., $\left.\frac{\partial Q_{i}^{S}}{\partial \delta_{j}}\right|_{\theta}$ is greater than or equal to the sum of $\left.\frac{\partial Q_{i}^{S}}{\partial \delta_{j}}\right|_{\alpha_{i}}$ and $\left.\frac{\partial Q_{i}^{S}}{\partial \delta_{j}}\right|_{z_{i}}$ in absolute value. Or equivalently, $\frac{\partial Q_{i}^{S}(\boldsymbol{p} ; \boldsymbol{\delta})}{\partial \delta_{j}} \geq 0$ for $j \neq i$

For proportional yield increases, the above conditions and the derivatives of (36) stay the same except for the replacement of $\delta$ by $\psi$. From (36), we can derive a result similar to Remark 3: if land share effect and input use effect dominate, then yield improvement for a crop will shift out its supply and shift in the supply of other crop; that is,

$$
\begin{aligned}
& \frac{\partial Q_{i}^{S}(\boldsymbol{p} ; \boldsymbol{\delta})}{\partial \delta_{i}}>0, \text { for } i=c \text { or } o \\
& \frac{\partial Q_{i}^{S}(\boldsymbol{p} ; \boldsymbol{\delta})}{\partial \delta_{j}}<0 \text { under condition } \mathrm{A}^{\prime} ; \geq 0 \text { under condition } \mathrm{B}^{\prime}, \text { for } j \neq i
\end{aligned}
$$

To see how such supply shifts affect prices, differentiating (12) with respect to $\delta_{i}$, we obtain

$$
\frac{d p_{o}(\boldsymbol{\delta})}{d \delta_{i}}=\frac{\partial Q_{o}^{S}(\boldsymbol{p} ; \boldsymbol{\delta})}{\partial \delta_{i}}\left[\frac{\partial Q_{o}^{D}(\boldsymbol{p})}{\partial p_{o}}-\frac{\partial Q_{o}^{S}(\boldsymbol{p} ; \boldsymbol{\delta})}{\partial p_{o}}\right]^{-1}
$$

Note that (39) does not consider adjustment in $p_{c}$, since $p_{c}$ is set at the breakeven corn price in ethanol production. From discussions related to (14), the denominator is positive. Given ( 37)(38), equation ( 39) implies $\frac{d p_{o}(\boldsymbol{\delta})}{d \delta_{o}}<0 ; \frac{d p_{o}(\boldsymbol{\delta})}{d \delta_{c}}>0$ under Condition $\mathrm{A}^{\prime} ; \frac{d p_{o}(\boldsymbol{\delta})}{d \delta_{c}} \leq 0$ under Condition B'. Combining these results with (26) and (29), we can obtain the effects on total cropland area at market equilibrium, i.e.,

$$
\frac{d \theta^{*}(\boldsymbol{\delta})}{d \delta_{i}}=\frac{\partial \theta^{*}(\boldsymbol{p} ; \boldsymbol{\delta})}{\partial \delta_{i}}+\frac{\partial \theta^{*}(\boldsymbol{p} ; \boldsymbol{\delta})}{\partial p_{o}} \frac{d p_{o}(\boldsymbol{\delta})}{d \delta_{i}} .
$$


For $i=c$, we see $\frac{d \theta^{*}(\delta)}{d \delta_{c}}>0$ under Condition A' since the right-hand side is the sum of two positive numbers. Under Condition B', the sign of $\frac{d \theta^{*}(\delta)}{d \delta_{c}}$ is not obvious: the first term on the right is positive while the second is negative. However, note that given the same corn price, the decrease in the price of other crop means reduced land share and input use and increased consumption for other crop at market equilibrium. Given the same yield for other crop, this can only occur if the total cropland area has increased, i.e., $\frac{d \theta^{*}(\delta)}{d \delta_{c}}>0$.

For $i=o$, the preceding argument related to Condition B' applies except at the last step: due to yield improvement for other crop, reduced share and input use can occur together with increased consumption without increases in total cropland area. From ( 26) and (29), we know $\varepsilon_{\theta^{*}, \delta_{i}}=\varepsilon_{\theta^{*}, p_{i}}$. Then, rearranging (40), we obtain

$$
\frac{d \theta^{*}(\delta)}{d \delta_{o}} \frac{\delta_{o}}{\theta^{*}}=\varepsilon_{\theta^{*}, \delta_{o}}\left(1+\varepsilon_{p_{o}, \delta_{o}}\right),
$$

which will be positive if $\varepsilon_{p_{o}, \delta_{o}}>-1$.

Proof of Proposition 5. If crop demand is perfectly elastic, then crop prices will not change at the new market equilibrium with higher yields. Total cropland area will adjust according to (29), which means that total cropland area expands at market equilibrium.

When crop demand is perfectly inelastic, then consumption of crops will stay the same at a different market equilibrium. Suppose total cropland area does not decline at the new market equilibrium with higher yields. We consider the two possible outcomes of land share and input use. First, land share and input use do not change. This, combined with higher yields and no decline in total cropland, means that the production of at least one crop is larger. Given that crop 
consumption does not change, the system cannot be in equilibrium. Second, land share and input use for one crop increase. Whether yield increases or not for the crop that is allocated with more cropland and input, there would be more production than consumption for this crop. The system cannot be in equilibrium either. Thus, we conclude that total cropland area must decline with yield increases given perfectly inelastic demand.

As for the condition at the end of the proposition, note that

$$
\begin{gathered}
\frac{d \alpha_{i}^{*}(\boldsymbol{\delta}, \theta)}{d \delta_{j}}=\frac{\partial \alpha_{i}^{*}(\boldsymbol{p} ; \boldsymbol{\delta}, \theta)}{\partial p_{c}} \frac{d p_{c}(\boldsymbol{\delta})}{d \delta_{j}}+\frac{\partial \alpha_{i}^{*}(\boldsymbol{p} ; \boldsymbol{\delta}, \theta)}{\partial p_{o}} \frac{d p_{o}(\boldsymbol{\delta})}{d \delta_{j}}+\frac{\partial \alpha_{i}^{*}(\boldsymbol{p} ; \boldsymbol{\delta}, \theta)}{\partial \delta_{j}} \\
\frac{d z_{i}^{*}(\boldsymbol{\delta}, \theta)}{d \delta_{j}}=\frac{\partial z_{i}^{*}(\boldsymbol{p} ; \boldsymbol{\delta}, \theta)}{\partial p_{c}} \frac{d p_{c}(\boldsymbol{\delta})}{d \delta_{j}}+\frac{\partial z_{i}^{*}(\boldsymbol{p} ; \boldsymbol{\delta}, \theta)}{\partial p_{o}} \frac{d p_{o}(\boldsymbol{\delta})}{d \delta_{j}}+\frac{\partial z_{i}^{*}(\boldsymbol{p} ; \boldsymbol{\delta}, \theta)}{\partial \delta_{j}}
\end{gathered}
$$

Remark 1 implies that the first two corresponding terms on the right of (42) and (43) have the same sign. From ( 30)-( 35), we know the last terms in the two equations also have the same sign. As one example, for $j=i=c$, the last terms are positive. If higher $\delta_{c}$ means lower $p_{c}$ and lower $p_{o}$, then the first two terms are negative. The net effect is then ambiguous for both equations. However, technically speaking, it may happen that the net result in (42) is positive while the net result in (43) is negative, or vice versa. The condition at the end of the proposition requires that this does not happen. 


\section{References:}

Arnade, C., and D. Kelch. 2007. "Estimation of Area Elasticities from a Standard Profit Function.” American Journal of Agricultural Economics 89(3) (August): 727-737

Arrow, K.J., H.D. Block, and L. Hurwicz. 1959. "On the Stability of the Competitive Equilibrium, II.” Econometrica 27 (1): 82-109.

Birur, D.K., T.W. Hertel, and W.E. Tyner. 2007. "The Biofuels Boom: Implications for World Food Markets." Presentation at the Food Economy Conference Sponsored by the Dutch Ministry of Agriculture, The Hague, October 18-19, 2007.

Chavas, J.-P., and M.T. Holt. 1990. "Acreage Decisions under Risk: The Case of Corn and Soybeans." American Journal of Agricultural Economics 72 (3) (August): 529-538.

Dale, B. 2008. "Response to Science Papers by Fargione et al., and Searchinger et al." http://www.ncga.com/ethanol/pdfs/2008/DaleResponseSciencexpressArticles.pdf.

Fargione,J., J. Hill, D. Tilman, S. Polasky, and P. Hawthorne. 2008. "Land Clearing and the Biofuel Carbon Debt.” Science 319 (5867): 1235-1238.

Farrell, A.E. 2008. "Better Biofuels before More Biofuels.” San Francisco Chronicle, February 13. http://www.sfgate.com/cgi-bin/article.cgi?f=/c/a/2008/02/13/EDGEV10VF.DTL.

Feng, H. O.D. Rubin, and B.A. Babcock. "Greenhouse Gas Impacts of Ethanol from Iowa Corn: Life Cycle Analysis versus System Wide Accounting." Working Paper 08-WP 461, Center for Agricultural and Rural Development, Iowa State University.

Hennessy, D.A. 2006. "On Monoculture and the Structure of Crop Rotations." American Journal of Agricultural Economics 88 (4): 900-914.

Keeney, R., and T. Hertel. 2008. "The Indirect Land Use Impacts of U.S. Biofuel Policies: The Importance of Acreage, Yield, and Bilateral Trade Responses.” GTAP Working Paper No. 52, Department of Agricultural Economics, Purdue University.

Monsanto. 2008. "Food and Fuel: It's not an 'either/or' equation." News and Media, http://monsanto.mediaroom.com/index.php?s=59\&item=167. 
Negishi, T. 1962. “The Stability of a Competitive Economy: A Survey Article.” Econometrica 30 (4): 635-669.

O’Hare, M. 2008.“Greenhouse Gas Emissions from Indirect Land Use Change.” Presentation at CARB LCFS Working Group 3. Sacramento, CA. http://www.arb.ca.gov/fuels/lcfs/011708UCBLUCB\&W.pdf.

Orazem, P.F., and J.A. Miranowski. 1994. "A Dynamic Model of Acreage Allocation with General and Crop-Specific Soil Capital.” American Journal of Agricultural Economics 76 (3) (August): 385-395

Righelato, R., and D.V. Spracklen. 2007 "Carbon Mitigation by Biofuels or by Saving and Restoring Forests?" Science, 317 (5840): 902.

Searchinger, T., R. Heimlich, R.A. Houghton, F. Dong, A. Elobeid, J. Fabiosa, S. Tokgoz, D. Hayes, and T. Yu. 2008. "Use of U.S. Croplands for Biofuels Increases Greenhouse Gases Through Emissions from Land Use Change.” Science 319 (5867): 1238-1240.

Wang, M., and A. Haq. 2008. Letter to Science in Response to "Use of U.S. Croplands for Biofuels Increases Greenhouse Gases through Emissions from Land Use Change.” Searchinger et al. http://www.transportation.anl.gov/pdfs/letter_to_science_anldoe_03_14_08.pdf.

Zulauf, C. 2007. "Food vs. Fuel vs. the Environment: Creating a Win-Win Solution through Yield.” Reports Series (AEDE-RP-0064-07), Department of Agricultural, Environmental, and Development Economics, Ohio State University. 